\title{
Chronic severe hepatitis and preoperative creatinine are independent risk factors for acute kidney injury after liver transplantation
}

\author{
Yingqi Chen, Shanshan Mu, Jing Wang, Anshi Wu \\ Department of Anesthesiology, Beijing Chao-Yang Hospital, Beijing, China \\ Contributions: (I) Conception and design: Y Chen, A Wu; (II) Administrative support: A Wu; (III) Provision of study materials or patients: S Mu; (IV) \\ Collection and assembly of data: J Wang; (V) Data analysis and interpretation: Y Chen; (VI) Manuscript writing: All authors; (VII) Final approval of \\ manuscript: All authors. \\ Correspondence to: Anshi Wu. Department of Anesthesiology, Beijing Chao-Yang Hospital, No. 8 Gongti South Road, Chaoyang District, Beijing \\ 100020, China. Email: angelaqiqi328@hotmail.com.
}

Background: Orthotopic liver transplantation (OLT) offers the highest chance of cure in comparison with
all other treatment for liver tumors and other end stage liver disease. However, the complications caused by
liver transplantation significantly affect its therapeutic effect, and acute kidney injury (AKI) is one of the most
common of these. It is, therefore, necessary to identify the risk factors of AKI after liver transplantation.
Methods: A single-center, retrospective study of patients receiving liver transplantation at the Beijing
Chao-Yang Hospital between January 2015 to January 2019 was conducted.
Patients were divided into a normal control group and AKI group based on their previous medical history.
Preoperative and intraoperative indicators including preoperative creatinine, uric acid, and the intraoperative
input of protein were then recorded.
Results: A total of 419 patients were enrolled into the study. The control group consisted of 336 patients
while 83 patients formed an AKI group based on the grading criteria of AKI. There were significant
differences in chronic severe hepatitis ( $\mathrm{P}=0.001)$, liver cancer $(\mathrm{P}=0.044)$, intraoperative input of sodium
bicarbonate ( $\mathrm{P}=0.019)$, input of red blood cell suspension ( $\mathrm{P}=0.004)$, the input of blood plasma (P=0.043),
intraoperative urine output $(\mathrm{P}=0.006)$, and preoperative creatinine $(\mathrm{P}=0.041)$ between the control and AKI
group. Multivariate analysis indicated that chronic severe hepatitis $(\mathrm{OR}: 2.872$; $\mathrm{P}=0.003)$ and preoperative
creatinine (OR: 1.083 ; $\mathrm{P}=0.011)$ were independent risk factors for AKI in patients receiving liver
transplantation.

Conclusions: Chronic severe hepatitis and preoperative creatinine may be potential risk factors for the occurrence of AKI after liver transplantation.

Keywords: Acute kidney injury (AKI); liver transplantation; risk factors; creatinine

Submitted Oct 28, 2020. Accepted for publication Dec 10, 2020.

doi: $10.21037 /$ atm-20-7680

View this article at: http://dx.doi.org/10.21037/atm-20-7680

\section{Introduction}

Orthotopic liver transplantation (OLT) offers the highest chance of cure in comparison with all other treatments including drug treatment and radiation therapy for the treatment of liver tumors and other end stage liver diseases (1). In general, patients who fail to respond to conservative treatment and may die within 6-12 months should be considered for OLT. As its availability increases in both developed and developing countries, OLT is being regarded as a standard therapy for early liver cancer $(1,2)$, however, the complications caused by OLT significantly impact on its treatment effect. Acute kidney injury (AKI) is 
Table 1 Characteristics of patients receiving OLT

\begin{tabular}{|c|c|c|c|c|c|c|c|c|}
\hline & \multicolumn{2}{|c|}{ Gender } & \multicolumn{4}{|c|}{ AKI } & \multicolumn{2}{|c|}{ Living status } \\
\hline $\mathrm{N}$ & 349 & 70 & 336 & 46 & 22 & 15 & 403 & 16 \\
\hline Percentage (\%) & 83.3 & 16.7 & 80.2 & 11.0 & 5.3 & 3.6 & 96.2 & 3.8 \\
\hline
\end{tabular}

a common complication following OLT, with an incidence of between $12 \%$ and $95 \%(3,4)$, and has been reported to increase the mortality of recipients after $\operatorname{OLT}(5,6)$.

While acute kidney disease usually occurs when kidney damage is present for less than 3 months, AKI can occur over as little as 7 days (7). Usually leading to a longer recovery time and a heavier economic burden for patients (8), AKI has been identified as an independent risk factor for death, especially in critically ill patients (9). The etiology of AKI after OLT is related to multiple factors, including renal ischemia, the influence of immunosuppressive drugs, and the general condition of patients $(10,11)$. Research evaluating OLT prior to 2015 is limited (12-14). Thus, it is necessary to identify the risk factors of AKI after OLT.

This study compared several preoperative and intraoperative factors in both a control and AKI group, with the aim of determining risk factors for the occurrence of AKI after OLT.

We present the following article in accordance with the STROBE reporting checklist (available at http://dx.doi. org/10.21037/atm-20-7680).

\section{Methods}

\section{Study design}

A single-center, retrospective study of patients receiving OLT in the Beijing Chao-Yang Hospital from January 2015 to January 2019 was conducted. The study was approved by the Beijing Chao-Yang Hospital Ethics Committee was conducted in accordance with the provisions of the Declaration of Helsinki (as revised in 2013). Medical records were collected with the consent of the patients involved.

Exclusion criteria: patients under 14 years of age were excluded from the study; those who had undergone kidney transplantation, and those who had incomplete laboratory data. The age, gender, and medical history of the following conditions were recorded; HBV cirrhosis, alcoholic cirrhosis, chronic severe hepatitis, liver cancer, congenital liver disease, liver failure, hepatitis B surface antigen, hepatitis C antibody, hypertension, diabetes, ascites, hepatorenal syndrome, upper gastrointestinal bleeding, liver coma, preoperative lung infections, and input of blood coagulation factor.

Perioperative levels of creatinine, uric acid, urea and urine specific gravity were recorded and intraoperative measures of protein input, Ringer's solution, sodium bicarbonate, intraoperative blood loss, input of red blood cell suspension and blood plasma, intraoperative urine output, operation time and intraoperative no-liver time.

\section{Patients}

Of the 419 patients, 349 were male and 70 female, and the average age was $47.74 \pm 11.34$. At time of writing, 403 (96.2\%) patients had survived, and $16(3.8 \%)$ patients were deceased. According to AKI grading criteria, there were $336(80.2 \%)$ normal patients and $83(19.9 \%)$ AKI patients (Table 1).

\section{Definition of AKI}

The Kidney Disease Improving Global Outcomes (KDIGO) criteria defines AKI as an abnormal rise of the serum creatinine after OLT (7). Moreover, the staging of AKI in patients receiving OLT is defined as (7) stage I: rise of $\geq 26 \mu \mathrm{mol} / \mathrm{L}$ or $0.3 \mathrm{mg} / \mathrm{dL}$ within $48 \mathrm{~h}$ or $50-99 \% \mathrm{Cr}$ rise from baseline within 7 days; stage II: 100-199\% Cr rise from baseline within 7 days; stage III: $\geq 200 \% \mathrm{Cr}$ rise from baseline within 7 days or (current) $\mathrm{Cr} \geq 354 \mu \mathrm{mol} / \mathrm{L}$, with either: rise of $\geq 26 \mu \mathrm{mol} / \mathrm{L}$ or $0.3 \mathrm{mg} / \mathrm{dL}$ within $48 \mathrm{~h}$ or $\geq 50 \% \mathrm{Cr}$ rise from baseline within 7 days or any requirement for renal replacement therapy. The specific number of patients in different stages is listed in Table 1 . Among the AKI patients, 46 patients were in stage I, 22 were in stage II, and 15 were in stage III.

\section{Statistical analysis}

The data was analyzed using SPSS 19.0 (IBM). Quantitative data were expressed as mean \pm standard deviation or median 
Table 2 Comparison of characteristics between patients with and without AKI

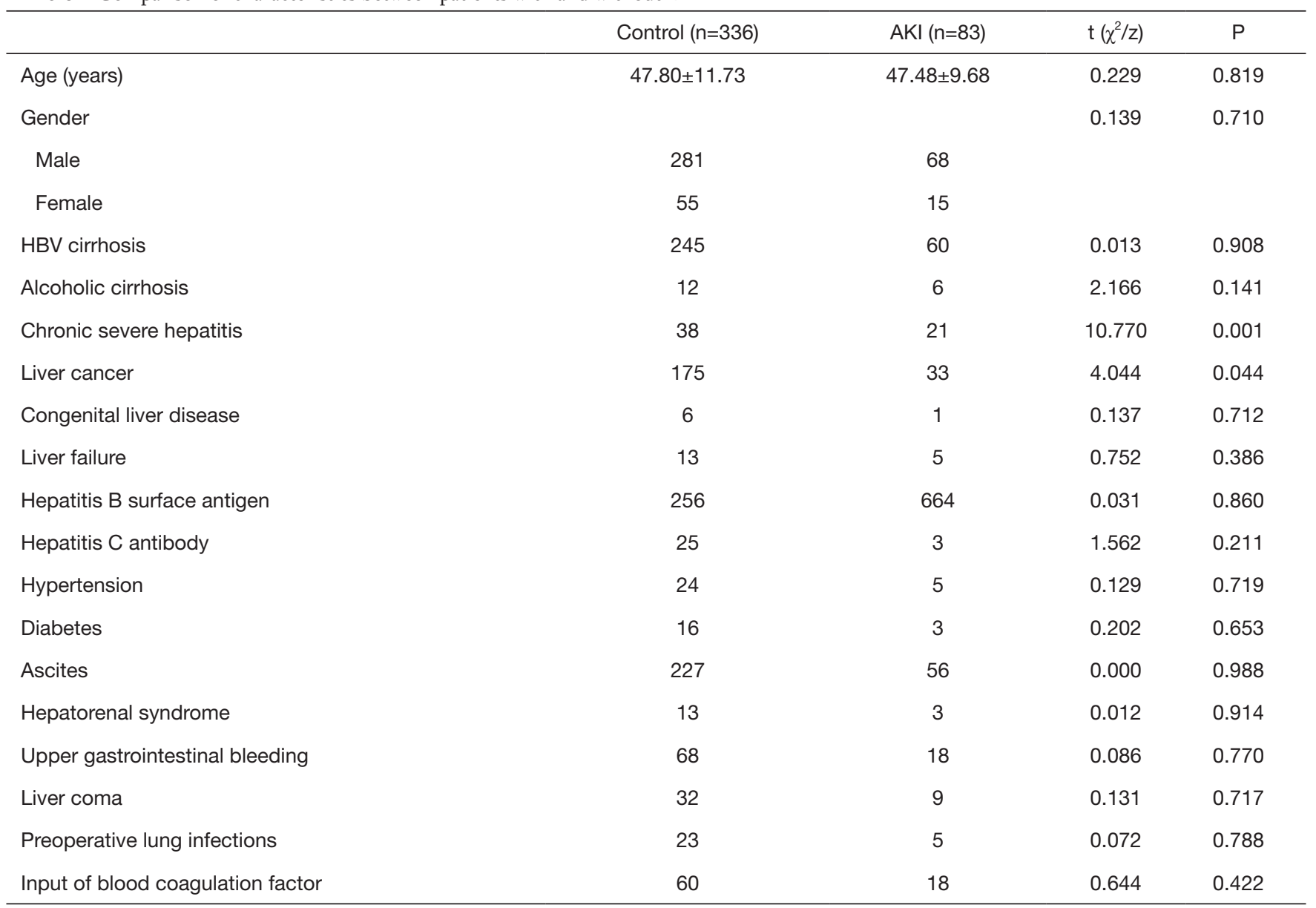

(interquartile range). Qualitative data were expressed as rates or composition ratios. Comparisons of normally distributed data between groups were analyzed by the $t$-test. Comparisons of non-normally distributed data between groups were analyzed by the rank-sum test. The categorical data were expressed as $\mathrm{n}(\%)$, and comparison of the two groups was examined by Pearson $\chi^{2}$ test or Fisher's exact test. Multivariate analysis was performed using a logistic multiple regression model, and risk factors were used to predict the occurrence of AKI using a ROC curve. $\mathrm{P}<0.05$ was considered statistically significant. If the odds ratio $(\mathrm{OR})$ of a factor is greater than 1 , then this factor is a risk factor for the disease.

\section{Results} Comparison of characteristics between patients with and
without AKI

A total of 419 patients were involved in this study. When the characteristics of the control group and the AKI group were compared (Table 2), no significant difference was found in age $(\mathrm{P}=0.819)$ and gender $(\mathrm{P}=0.710)$ between the two.

A history of chronic severe hepatitis was significantly different $(11.31 \%$ in control vs. $25.30 \%$ in $\mathrm{AKI} ; \mathrm{P}=0.001)$ between the groups, as was liver cancer $(52.08 \%$ in control vs. $39.76 \%$ in $\mathrm{AKI} ; \mathrm{P}=0.044)$, while there were no difference between the groups in the status of HBV cirrhosis $(\mathrm{P}=0.908)$, alcoholic cirrhosis $(\mathrm{P}=0.141)$, congenital liver disease $(\mathrm{P}=0.712)$, liver failure $(\mathrm{P}=0.386)$, hepatitis $\mathrm{B}$ surface antigen $(\mathrm{P}=0.860)$, and hepatitis $\mathrm{C}$ antibody $(\mathrm{P}=0.211)$.

There were also no significant differences in the two groups between patients with a history of other diseases, including hypertension $(\mathrm{P}=0.719)$, diabetes $(\mathrm{P}=0.653)$, ascites $(\mathrm{P}=0.988)$, hepatorenal syndrome $(\mathrm{P}=0.914)$, upper gastrointestinal bleeding $(\mathrm{P}=0.770)$, liver coma $(\mathrm{P}=0.717)$, preoperative lung infections $(\mathrm{P}=0.788)$, and input of blood coagulation factor $(\mathrm{P}=0.422)$. 
Table 3 Comparison of preoperative and intraoperative indicators between patients with and without AKI

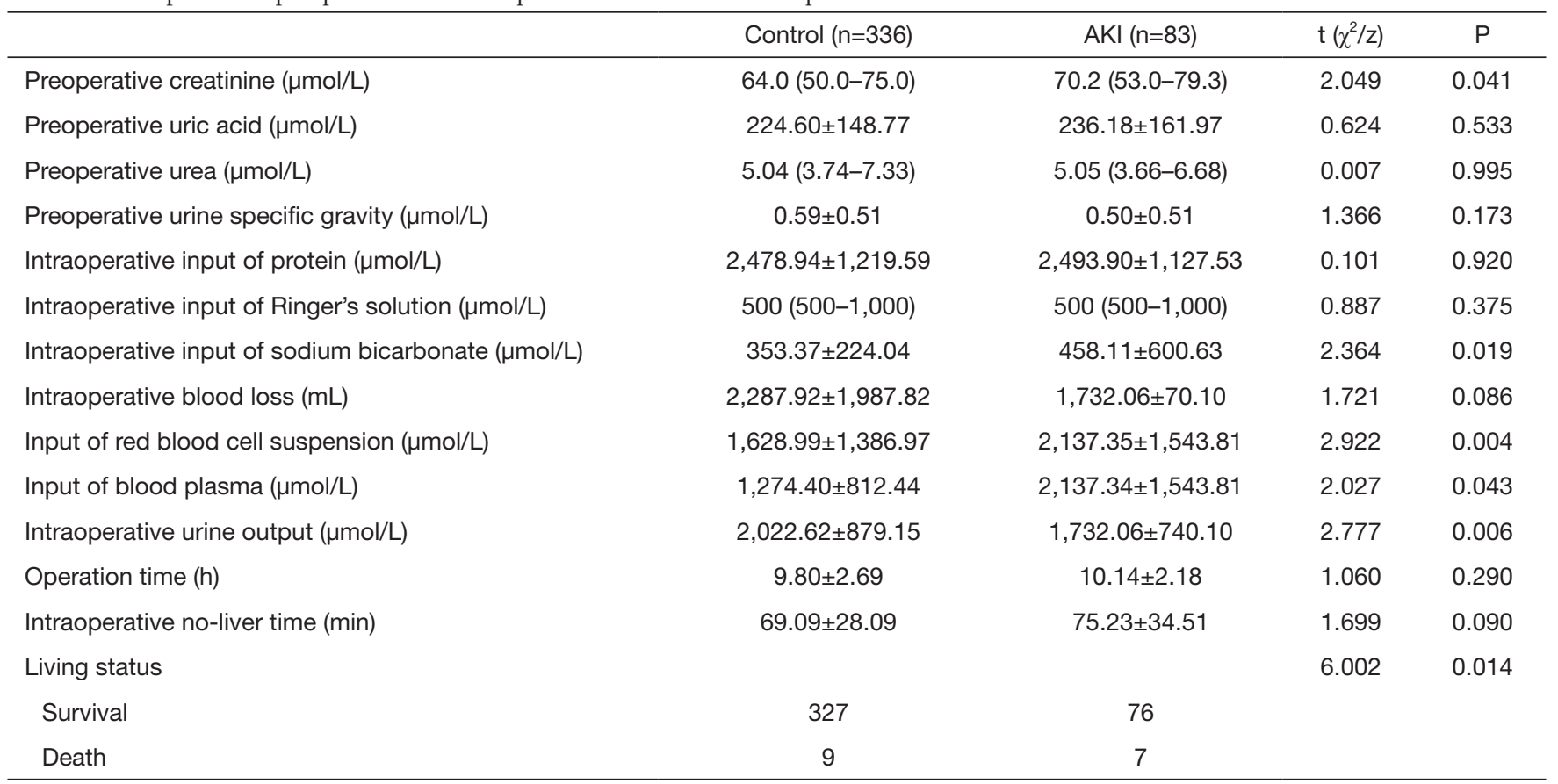

\section{Comparison of preoperative and intraoperative indicators}

A comparison of preoperative and intraoperative indicators is shown in Table 3. Preoperative indicators including uric acid $(\mathrm{P}=0.533)$, urea $(\mathrm{P}=0.995)$ and urine specific gravity $(\mathrm{P}=0.173)$ showed no difference whereas preoperative creatinine was significantly higher in the AKI group in comparison to the control group ( $\mathrm{P}=0.041)$.

Intraoperative indicators including the input of protein, input of Ringer's solution, blood loss, operation time, and no-liver time were not different in patients with and without AKI. However, the intraoperative input of sodium bicarbonate $(\mathrm{P}=0.019)$, input of red blood cell suspension $(\mathrm{P}=0.004)$, and input of blood plasma $(\mathrm{P}=0.043)$ were significantly higher in the AKI group, which may be related to the significantly decreased intraoperative urine output $(\mathrm{P}=0.006)$ in that group compared with the control group. Importantly, the living status was significantly different $(\mathrm{P}=0.014)$, as $327(97.32 \%)$ patients survived in the control group while 76 (91.57\%) survived in the AKI group.

\section{Evaluation of risk factors for AKI in patients receiving $O L T$}

A multivariate analysis was formed to identify risk factors for AKI in patients receiving OLT (Table 4). Chronic severe hepatitis (OR: 2.872; 95\% CI: 1.429-5.772; $\mathrm{P}=0.003$ ) and preoperative creatinine (OR: 1.083; 95\% CI: 1.071-1.096; $\mathrm{P}=0.011$ ) were independent risk factors for AKI in patients receiving OLT.

Other factors were not significant, including the intraoperative input of sodium bicarbonate $(\mathrm{P}=0.169)$, input of red blood cell suspension $(\mathrm{P}=0.076)$, the input of blood plasma $(\mathrm{P}=0.979)$, intraoperative blood loss $(\mathrm{P}=0.172)$, and intraoperative no-liver time $(\mathrm{P}=0.641)$. Although the $\mathrm{P}$-value was less than 0.05 in the hypothesis test regarding the correlation between intraoperative urine output and AKI, the OR value was equal to 1 , suggesting that this was not a risk factor.

\section{Predictive value of factors for AKI occurrence}

The predictive value of factors for AKI occurrence was studied by drawing ROC curves (Figure 1). As shown in Table 5, four significant predictors were found, including preoperative creatinine ( $\mathrm{AUC}=0.577 ; \mathrm{P}=0.031$ ), intraoperative urine output ( $\mathrm{AUC}=0.591 ; \mathrm{P}=0.011$ ), input of red blood cell suspension ( $\mathrm{AUC}=0.611 ; \mathrm{P}=0.002$ ), and intraoperative blood loss ( $\mathrm{AUC}=0.572 ; \mathrm{P}=0.042$ ).

\section{Discussion}

As a common complication following OLT, AKI is associated with a poor prognosis and sometimes death. 
Table 4 Multivariate analysis of AKI in patients receiving OLT

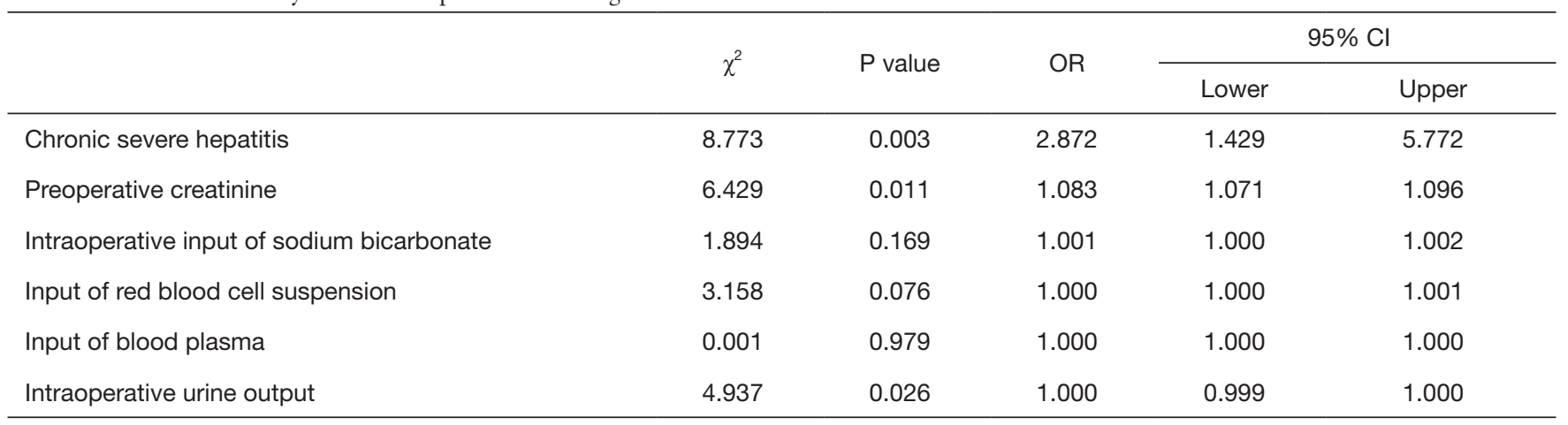
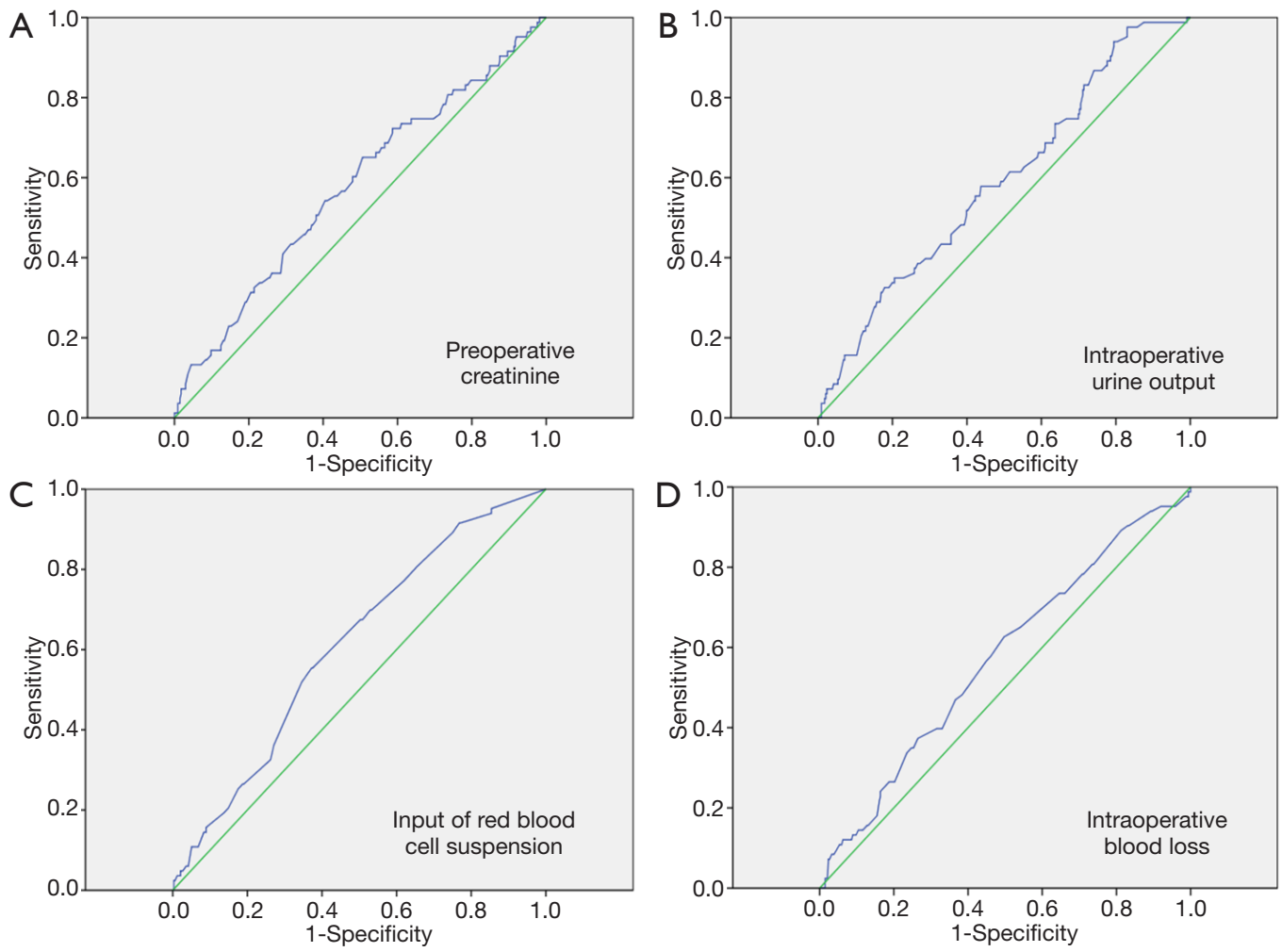

Figure 1 Predictive value of $(\mathrm{A})$ preoperative creatinine $(\mathrm{P}=0.031),(\mathrm{B})$ intraoperative urine output $(\mathrm{P}=0.011),(\mathrm{C})$ input of red blood cell suspension ( $\mathrm{P}=0.002)$, and $(\mathrm{D})$ intraoperative blood loss $(\mathrm{P}=0.042)$ for AKI occurrence.

The incidence rate of AKI in patients receiving OLT in this study was $19.8 \%$, which is lower than that seen in previous studies. Cabezuelo et al. reported the postoperative, first-month overall incidence of acute renal failure following OLT was $48 \%$ (15) while Sirivatanauksorn et al. found an even higher incidence rate of $71.6 \%$ during the first week (16). The use of newly announced criteria of the Kidney Disease Improving Global Outcomes (KDIGO) may account for the lower rate seen in our study.
Although more than half of the AKI patients in this study were in the less severe stage 1 of the disease, there was a higher incidence of death in that group in comparison to the control group. To assess the severity of liver disease, the Model for End-stage Liver Disease (MELD) classification has been put forward. Some doctors have related higher MELD score and Child-Pugh grade with AKI after OLT (17).

Confirming results seen in other studies, in comparison to the control group, the AKI group in this study had a 
Table 5 Predictive value of factors for AKI occurrence by ROC curves

\begin{tabular}{lcccc}
\hline \multirow{2}{*}{ Predictors } & \multicolumn{4}{c}{ ROC curves } \\
\cline { 2 - 5 } & Cut-off value & AUC & $95 \% \mathrm{Cl}$ & P value \\
\hline $\begin{array}{l}\text { Preoperative } \\
\text { creatinine }(\mu \mathrm{mol} / \mathrm{L})\end{array}$ & 145.7 & 0.577 & $0.506-0.647$ & 0.031 \\
$\begin{array}{l}\text { Intraoperative urine } \\
\text { output }(\mu \mathrm{mol} / \mathrm{L})\end{array}$ & 272.5 & 0.591 & $0.523-0.658$ & 0.011 \\
$\begin{array}{l}\text { Input of red blood cell } \\
\text { suspension ( } \mu \mathrm{mol} / \mathrm{L})\end{array}$ & 1725 & 0.611 & $0.546-0.675$ & 0.002 \\
$\begin{array}{l}\text { Intraoperative blood } \\
\text { loss }(\mathrm{mL})\end{array}$ & 1650 & 0.572 & $0.504-0.640$ & 0.042 \\
\hline
\end{tabular}

higher incidence of chronic severe hepatitis and this was found to be an independent risk factor for AKI in patients receiving OLT. This suggests that patients with chronic severe hepatitis and poor condition should receive special attention and care after surgery.

Supporting the results of Zongyi et al. (18), our results also show that preoperative creatinine is an independent risk factor for AKI and shows moderate predictive ability. In their multicenter study of 5074 patients, the average preoperative serum creatinine of the AKI group was 85 (64-136), significantly higher than that of the control group of $74.6(56.2-110)$ and their multivariate analysis showed preoperative serum creatinine $(>354 \mu \mathrm{mol} / \mathrm{L})$ was a risk factor (OR: 1.352; 95\% CI: 1.181-1.763; $\mathrm{P}<0.001)$. The relatively high preoperative serum creatinine may result from the unavoidable whole body ischemia occurring during OLT $(8,19)$. To prioritize the blood supply to other important organs, a transitory insufficient supply to the kidney may occur, causing tubular necrosis (20). This study is limited by its single-center, retrospective design and only moderate number of participants. Multi-center, prospective studies with larger cohorts are required to confirm the results.

\section{Conclusions}

In summary, chronic severe hepatitis and high preoperative creatinine levels may be potential risk factors for the occurrence of AKI after OLT.

\section{Acknowledgments}

Funding: This work was supported by the Key Projects of Sailing Plan of Beijing Medical Administration (no.

\section{ZYLX201822).}

\section{Footnote}

Reporting Checklist: The authors have completed the STROBE reporting checklist. Available at http://dx.doi. org/10.21037/atm-20-7680

Data Sharing Statement: Available at http://dx.doi. org/10.21037/atm-20-7680

Conflicts of Interest: All authors have completed the ICMJE uniform disclosure form (available at http://dx.doi. org/10.21037/atm-20-7680). The authors have no conflicts of interest to declare.

Ethical Statement: The authors are accountable for all aspects of the work in ensuring that questions related to the accuracy or integrity of any part of the work are appropriately investigated and resolved. The clinical study was approved by the Ethics Committee of Beijing ChaoYang Hospital and was conducted in accordance with the provisions of the Declaration of Helsinki (as revised in 2013). Written informed consent was obtained from all participants before enrolment.

Open Access Statement: This is an Open Access article distributed in accordance with the Creative Commons Attribution-NonCommercial-NoDerivs 4.0 International License (CC BY-NC-ND 4.0), which permits the noncommercial replication and distribution of the article with the strict proviso that no changes or edits are made and the original work is properly cited (including links to both the formal publication through the relevant DOI and the license). See: https://creativecommons.org/licenses/by-nc-nd/4.0/.

\section{References}

1. Sapisochin G, Bruix J. Liver transplantation for hepatocellular carcinoma: outcomes and novel surgical approaches. Nat Rev Gastroenterol Hepatol 2017;14:203-17.

2. Kow AW. Transplantation versus liver resection in patients with hepatocellular carcinoma. Transl Gastroenterol Hepatol 2019;4:33.

3. Klaus F, Keitel da Silva C, Meinerz G, et al. Acute Kidney Injury After Liver Transplantation: Incidence and Mortality. Transplant Proc 2014;46:1819-21.

4. Karapanagiotou A, Kydona C, Dimitriadis C, et al. Acute 
Kidney Injury After Orthotopic Liver Transplantation. Transplant Proc 2012;44:2727.

5. O'Riordan A, Wong V, McQuillan R. et al. Acute Renal Disease, as Defined by the RIFLE Criteria, Post-Liver Transplantation. Am J Transplant 2007;7:168-76.

6. Chen J, Singhapricha T, Hu KQ, et al. Postliver Transplant Acute Renal Injury and Failure by the RIFLE Criteria in Patients With Normal Pretransplant Serum Creatinine Concentrations: A Matched Study. Transplantation 2011;91:348-53.

7. Thomas ME, Blaine C, Dawnay A, et al. The definition of acute kidney injury and its use in practice. Kidney Int 2015; 87:62-73.

8. Leithead JA, Rajoriya N, Gunson BK, et al. The evolving use of higher risk grafts is associated with an increased incidence of acute kidney injury after liver transplantation. J Hepatol 2014; 60:1180-6.

9. Clec'h C, Gonzalez F, Lautrette A, et al. Multiple-center evaluation of mortality associated with acute kidney injury in critically ill patients: a competing risks analysis. Crit Care 2011;15:R128.

10. Junge G, Schewior LV, Kohler S, et al. Acute Renal Failure After Liver Transplantation: Incidence, Etiology, Therapy, and Outcome. Transplant Proc 2006;38:723-4.

11. Gomes Junior RM, Cezar LC, Meneses GC, et al. Preoperative risk factors for acute kidney injury after liver transplantation: results from a cross-sectional study in northeast of brazil. Arq Gastroenterol 2018;55:18-22.

Cite this article as: Chen $\mathrm{Y}, \mathrm{Mu} \mathrm{S}$, Wang J, Wu A. Chronic severe hepatitis and preoperative creatinine are independent risk factors for acute kidney injury after liver transplantation. Ann Transl Med 2020;8(24):1663. doi: 10.21037/atm-20-7680
12. Huang J, Millis JM, Mao Y, et al. A pilot programme of organ donation after cardiac death in China. Lancet 2012;379:862.

13. Huang J. Ethical and legislative perspectives on liver transplantation in the People's Republic of China. Liver Transpl 2007;13:193-6.

14. Caplan A.L, Danovitch G, Shapiro M, et al. Time for a boycott of Chinese science and medicine pertaining to organ transplantation. Lancet 2011;378:1218.

15. Cabezuelo JB, Ramírez P, Ríos A, et al. Risk factors of acute renal failure after liver transplantation. Kidney Int 2006;69:1073-80.

16. Sirivatanauksorn Y, Parakonthun T, Premasathian $\mathrm{N}$, et al. Renal Dysfunction After Orthotopic Liver Transplantation. Transplant Proc 2014;46:818-21.

17. Utsumi M, Umeda Y, Sadamori H, et al. Risk factors for acute renal injury in living donor liver transplantation: evaluation of the RIFLE criteria. Transpl Int 2013;26:842.

18. Zongyi Y, Baifeng L, Funian Z, et al. Risk factors of acute kidney injury after orthotopic liver transplantation in China. Sci Rep 2017;7:41555.

19. Barreto AGC, Daher EF, Junior GBS, et al. Risk factors for acute kidney injury and 30-day mortality after liver transplantation. Ann Hepatol 2015;14:688-94.

20. Wadei HM, Abader P, Alsaad AA, et al. Arterial Blood Pressure at Liver Transplant Evaluation Predicts Renal Histology in Candidates With Renal Dysfunction. Liver Transpl 2019;25:1756. 